cable is essential. It must be emphasized that while some manufacturers claim their cold-filling joints are permanent, these joints are primarily for emergency use, and permanent repairs usually have to be carried out later. Failure to appreciate the necessity for very efficient mixing was, in fact, the cause of the breakdown of an $11-\mathrm{kv}$. joint after three months' operation. Another undertaking has come to the conclusion that the use of these joints is advantageous for cables of $33-\mathrm{kv}$. and higher, considering the saving of approximately a day and a half in the repair work worth while. In the bridging of cables across craters, many devices have been widely adopted, such as the use of scaffold poles as supports and the suspension of the cables temporarily on adjacent walls. Another scheme is the utilization of steel structures to support the cables temporarily while other parties requiring access to the crater attend to their work. These steel structures, which are generally covered with boarding to give the cable protection against stray splinters of anti-aircraft shells, etc., are erected rapidly and leave an almost clear space around for other work to be undertaken.

Practically all undertakings have now come to the conclusion that there is nothing to be gained by attempting anything in the way of actual repairs, apart from isolating bad sections of the system and restoring supplies to sound sections by means of alternative switching, while the raid is still in progress, except in very special circumstances: Apart from the unwarranted risk to personnel, little can be done until daylight. Much time and money is spent unnecessarily on having emergency repair gangs on duty throughout the twenty-four hours, and without any question of slackness it has been proved in practice that a much more satisfactory arrangement is to have the men standing by in their own homes and to call them up by telephone, or even by messenger, only when actually needed.

\section{MARINE RESEARCH IN THE UNITED STATES}

$\mathrm{T}$ HE eight papers in the latest number of the Journal of Marine Research* deal with,all aspects of oceanography, physical, chemical, biological and bacteriological.

A. H. Woodcock continues an earlier inquiry into the effect of cold winds on a water surface. In shallow water the cooled surface water finds its way downwards by converging into small-scale streamings about $1 \mathrm{~cm}$. across and several centimetres apart running parallel downwind. In vertical section a shallow surface stratum is broken up into a series of convection cells, and at the surface there are alternate convergent and divergent strips. In the open sea the small-scale streaming is present on the surface of the large waves, but there is also a large-scale convection mechanism with streams 50-100 ft. apart. On the small scale, lycopodium powder dusted over the surface falls at once into the linear pattern, and the gathering of Sargassum weed into parallel strips under the influence of a cooling wind is used as evidence of large convection cells.

* Journal of Marine Research, Vol. 4, No. 2, 1941. Sears Foundation for Marine Research, Bingham Oceanographic Laboratory, Yale University
Whitney describes measurements of the scattering of daylight in sea water. Whatever the altitude of the sun the light becomes more and more vertical as it penetrates, until it appears to reach an equilibrium distribution in which the light received from below is about half that received horizontally and roughly a fortieth of that from above. The depth at which such equilibrium is reached seems to vary between 5 and 30 metres according to the turbidity of the water. The measurements were made off the United States Atlantic coast and in a freshwater lake.

The waters off the United States Pacific coast are described by R. B. Tibby, who has measured the proportions of subarctic and equatorial waters in a broad coastal belt.

The first of the chemical papers deals with the $\mathrm{Na} / \mathrm{Cl}^{\prime}$ ratio in sea water. The relative concentration of all important ions in the sea is remarkably constant, but Robinson and Knapman, using a direct analytical method, have found a slightly higher ratio of $\mathrm{Na}$. to $\mathrm{Cl}^{\prime}$ in the coastal waters of Puget Sound than in the open Pacific Ocean. The method will be of great value in studying small variations or continuous trends in the composition of sea water.

Sanderman and Utterback, measuring the radium content of bottom sediments off the west coast of America from Canada to the Arctic Ocean, confirm the earlier conclusion that deep sea sediments are richer in radium than those of the land areas, and that the concentration is largely confined to a very thin surface film. Their richest sample was one that was just skimmed from the sea bed, so fine that it took several days to settle. While admitting that the plankton is $100-1,000$ times as rich in radium as the surrounding water they agree with earlier workers that the role of plankton as a carrier of radium to the bottom is likely to be negligible; their sediments from the regions of most abundant plankton were no richer than those from the most barren areas.

The biological papers deal mainly with the phytoplankton. W. E. Allen discusses the mechanism by which diatoms suspend themselves at levels favourable for their growth, or in some way keep contact with them. He considers their production of oils and gases, methods by which they can exert more or less friction on the surrounding water, and the possible effects of turbulent water movements. He believes that there are no reliable data for estimating the rate of sinking, laboratory methods lacking dependability for estimating the rates under complex sea conditions.

Gordon A. Riley summarizes his work on the plankton of the western North Atlantic in a diagram which illustrates the relationships between the phytoplankton and its environment. He makes an attempt to give algebraic expressions for the relative importance of the different factors. The equations. need testing, and are likely to apply better to average than particular conditions, but they give some hope that the phytoplankton production will eventually be predictable with some accuracy.

A bacteriological paper is by C. W. Hock, who has isolated bacteria capable of decomposing chitin, the tough leathery substance found in both rigid and flexible parts of most invertebrates. The bacteria which attack this very inactive substance have been found in sea water, marine sands and muds, and in the intestines of several marine animals. Two species are described, both aerobic ; ammonia-reducing substances and organic acids were among the products of decomposition.
G. E. R. DEACoN. 